\title{
As Peculiaridades das Ocupações Irregulares no Distrito Federal
}

\author{
BLANCO, Karoline Cunha ${ }^{1}$ \\ 1Programa de Pós-Graduação Faculdade de Arquitetura e Urbanismo, \\ Universidade de Brasília, Brasília, Brasil. blanco.karoline@gmail.com
}

\section{Resumo}

Considerando as peculiaridades apresentadas pelas ocupações irregulares no território do Distrito Federal foi realizado um apanhado sobre as conceituações atribuídas a esse formato de ocupação e desenvolvido um breve histórico que busca identificar as origens do problema. O estudo resulta em uma reflexão sobre as dimensões do problema das ocupações irregulares no território do Distrito Federal, bem como na relevância atribuída à denominação frente à busca de solução para a problemática apresentada. Busca-se um panorama sobre a situação do Distrito Federal diante ao crescimento desenfreado das ocupações irregulares visando subsídios para o desenvolvimento de estudos que investiguem possíveis soluções ou estratégias de mitigação para os problemas originários das ocupações irregulares.

Palavras-Chave: Ocupações irregulares, Distrito Federal, Condomínios.

\begin{abstract}
Considering the peculiarity presented by the illegal occupation in the territory of the Federal District was conducted an overview of the concepts assigned to that occupation format and developed a brief history that seeks to identify the origins of the problem. The study results in a reflection on the dimensions of the problem of illegal occupation in the territory of the Federal District, as well as the importance attached to the name front the search for a solution to the problems presented. Seeks an overview of the situation of the Federal District on the rampant growth of illegal occupation aimed subsidies for the development of studies to investigate possible solutions or mitigation strategies for the problems arising from illegal occupation.
\end{abstract}

Key-Words: Irregular Occupations, Federal District, Condominiums. 


\section{Introdução}

A irregularidade na forma de ocupação é um fenômeno que acomete todo o território brasileiro devido à necessidade de moradias pela população que não é atendida totalmente pelo modelo de planejamento atotado e pelas políticas públicas vigentes. No entanto, o Distrito Federal possui certas peculiaridades quanto à abrangência da população que se insere no formato irregular de ocupações.

As diferentes denominações atribuídas às ocupações irregulares numa tentativa de conceituar as suas variações acaba por dificultar uma avaliação mais precisa do problema.

No caso do Distrito Federal, as suas peculiaridades quanto à dominialidade das terras, as classes econômicas da população que ocupam os assentamentos, políticas públicas adotadas e o crescimento exponencial das ocupações irregulares agravam o quadro de falta de informações que possibilitem que o problema seja mensurado e mitigado.

A pesquisa é um apanhado de informações relacionadas às ocupações irregulares no Distrito Federal buscando analisar o problema diante das denominações atribuídas, do contexto histórico e dos dados apresentados de forma a subsidiar futuros estudos que abranjam o tema.

\section{Conceituação das Ocupações Irregulares}

As ocupações irregulares são um fenômeno cada vez mais comum devido ao crescimento populacional e a necessidade de moradia advinda deste crescimento. Essas ocupações surgem em variados espaços e premeiam diferentes classes sociais, dessa forma, vários conceitos surgem na tentativa de criar uma classificação dessa forma de ocupação que ocorre na contramão do que prevê as normas e leis de planejamento urbano.

Existe uma distinção, identificada por Moura (2008), entre irregularidade e ilegalidade. A irregularidade é ligada a situação de propriedade fundiária e a ilegalidade ao ato de parcelamento do solo. Considerando esta distinção, tem sido atribuída maior gravidade a ilegalidade, enquanto a possível regularização confere à irregularidade a possibilidade de solução.

Quanto à regularidade dos parcelamentos é feita e seguinte classificação (GDF, 2006 apud MOURA, 2008, p.13):

- Informais: Aqueles parcelamentos urbanos promovidos por particulares em terras públicas ou privadas, implantados (com ou sem processo de regularização), ou não implantados, mas que possuem processo de regularização aberto antes da aprovação do PDOT/97.

- Formais: Parcelamentos urbanos promovidos por particulares em terras privadas e que contam com processo de aprovação em andamento no GDF.

- Registrados: Parcelamentos urbanos que cumpriram todo o processo de regularização ou de aprovação estabelecido pelo poder público e que foram registrados em cartório.

Muitas vezes o conceito de moradia confunde-se com o acesso à propriedade. Lorenzetti (2001) aponta que a moradia é mais do que uma necessidade, é também "identificada como um direito que integra à subsistência, o qual, por sua vez, representa a expressão mínima do direito à vida". A moradia não é apenas um mero abrigo, mas engloba todos os componentes necessários para o morar digno que são: saneamento, infraestrutura, serviços e equipamentos urbanos.

O termo 'favela' é o mais utilizado na denominação de áreas habitacionais precárias de ocupação ilegal. Segundo Lorenzetti (2001) a favela é caracterizada pela ilegalidade quanto à posse da terra e pela precariedade das moradias ou ainda pela falta de acesso aos serviços públicos, mas não necessariamente pela localização periférica dos assentamentos.

Souza (2001) apresenta as favelas como áreas ocupadas à revelia das leis e normas estabelecidas e 
que a situação é agravada pelos processos intensivos de verticalização e densificação.

O IBGE reuniu todas as denominações conhecidas por todo o país como: favela, comunidade, grotão, vila, mocambo entre outros, na classificação de aglomerados subnormais. Aglomerados subnormais ${ }^{1}$, consiste, em linhas gerais, em áreas ocupadas irregularmente com limitação de ofertas de serviços urbanos e irregularidades no padrão urbanístico.

As favelas são áreas predominantemente ocupadas por setores da população de baixa renda, conforme apresentado por Brandão (2013). Assim, o modelo de ocupações irregulares do Distrito Federal, que foge aos padrões do restante do país, faz surgir uma nova denominação para este formato de ocupação em seu território, os condomínios.

Brandão (2013) aponta que o termo 'condomínio' passou a ser utilizado como referência a todo loteamento urbano que não cumpriu a lei em algum momento da sua constituição e consolidação. $O$ rótulo é aplicado independentemente da faixa de renda dos ocupantes, da conceituação jurídica de condomínio, cercamento ou regularidade.

A política habitacional de regularização do Distrito Federal configura-se como um caso particular em que a irregularidade fundiária não se restringe as ocupações de renda baixa, conhecidas como favelas no restante do país, mas atinge também grande parte da população de média e alta renda. A diferença fundamental seria a não escassez de bens e serviços públicos nos chamados condomínios horizontais irregulares no Distrito Federal.

Pode ser observada que a denominação adotada no DF é uma tentativa de fuga do estereótipo criado em relação ao termo favela. Moura (2013) aponta a tendência apresentada pelas ocupações coletivas em regiões periféricas de Brasília, antes denominadas invasões, de adotarem a terminologia condomínio originária dos segmentos médios e altos. Moura (2008) ainda acrescenta que os condomínios do Distrito Federal podem ser denominados 'favelas de luxo'.

\section{Histórico de Ocupações Irregulares no Distrito Federal}

Para possibilitar a transferência da capital do Brasil para o centro do país foi necessária a desapropriação de várias fazendas que ocupavam a área e, dessa forma, o governo passou a ser o proprietário dessas terras e gerir a sua utilização. Ainda nos dias atuais a gestão das terras do Distrito Federal é feita pela Companhia Imobiliária de Brasília - TERRACAP.

Brandão (2013) aponta que a interrupção do processo formal de desapropriação das inúmeras fazendas existentes na região do Distrito Federal, há época da implantação de Brasília, contribuíram para a escala alcançada do problema da irregularidade e que o domínio estatal de $60 \%$ das terras existentes no interior do quadrilátero já foi suficiente para construir um gigantesco estoque.

Este cenário possibilitou o surgimento de várias ocupações em áreas sob gestão do governo em todo o território do Distrito Federal e não necessariamente ocupações pela parcela menos favorecida da população, mas também de população de média e alta renda.

O histórico de invasões no Distrito Federal inicia-se junto a implantação da cidade de Brasília. Aqueles que vieram para prestar serviços na construção e demais trabalhadores que não se encaixavam no perfil para a qual a cidade foi concebida não poderiam permanecer na parte central da cidade, o Plano Piloto, e dessa forma, as invasões fizeram surgir às cidades satélites. As invasões se tornaram cidades, ou

\footnotetext{
1“Aglomerado subnormal é um conjunto constituído de, no mínimo, 51 unidades habitacionais (barracos, casas, etc.) carentes, em sua maioria de serviços públicos essenciais, ocupando ou tendo ocupado, até período recente, terreno de propriedade alheia (pública ou particular) e estando dispostas, em geral, de forma desordenada e/ou densa". (IBGE, 2010)
} 
condomínios, como costumam ser denominados atualmente, e agora buscam regularização.

De acordo com o apresentado pela Terracap (2016) já era possível encontrar ocupações irregulares no entorno do Distrito Federal já no início do processo de desapropriação de terras para a transferência da Capital Federal. Como exemplo são citados os loteamentos Nossa Senhora de Fátima, na Fazenda Mestre D’ Armas e Planaltinópolis, na Fazenda Paranoá.

$\mathrm{Na}$ década de 70 surge o primeiro parcelamento urbano irregular do Distrito Federal conhecido como "Condomínio Quintas da Alvorada", porém, a falta de infraestrutura e a quantidade de oferta de moradia regular não tornavam esse tipo de ocupação interessante para a população.

$\mathrm{Na}$ década de 80 a oferta de moradia regular decresce e o preço dos alugueis sobe. Dessa forma, começam a surgir os chamados 'condomínios' localizados, principalmente, na zona rural do Distrito Federal.

No ano de 1995, o Governo do Distrito Federal constituiu o Grupo Executivo de Trabalho para Parcelamentos Irregulares - GET - PI, cujo relatório desenvolvido naquele ano revelou a existência de 529 condomínios irregulares, dos quais somente 232 apresentavam condições para a continuidade do seu processo de regularização. Do total de condomínios que apresentavam condições de regularização 212 estavam em área desapropriada e sobre gestão da Terracap. (TERRACAP, 2016)

Em 2006 foi desenvolvido o "Diagnóstico Preliminar dos Parcelamentos Urbanos Informais no Distrito Federal" que subsidiou a elaboração da "Estratégia de Regularização Fundiária" que consta na revisão do Plano Diretor de Ordenamento Territorial do Distrito Federal - PDOT. Segundo dados apresentados pela Terracap (2016) o levantamento revelou a existência de 513 parcelamentos irregulares, dos quais 379 foram constituídos em zona urbana e 134 em zona rural. Dos parcelamentos urbanos, 347 eram informais, 28 estavam em processo de regularização e 4 eram regulares já registrados em cartório.

Segundo Brandão (2013), no Distrito Federal a busca dos setores de média e alta renda por condomínios horizontais afastados ocorre de maneira distinta devido a estrutura fundiária obscura advinda dos processos incompletos de desapropriação realizados na transferência da capital e também por arranjos institucionais existentes em diversos momentos de sua história.

Ainda de acordo com os estudos do autor, a disseminação de condomínios no DF ocorre em três ondas distintas. A primeira surge no final do ano 1970 e metade do ano de 1980, a segunda ocorre entre 1989 e 1994, quando houve ampla distribuição irregular de terras rurais públicas posteriormente transformada em condomínios, e a terceira ocorreu entre 1999 e 2002. Dessa forma, a regularização de condomínios ganha "centralidade na política local".

Brandão ainda aponta que três condições conjuntas foram suficientes para o início das ocorrências dos condomínios irregulares no Distrito Federal. A primeira foi o insulamento burocrático promovido pelo regimento autoritário que permitia interesses particulares entremeados à política. A segunda foi a obscuridade dos registros de algumas fazendas desapropriadas no início de Brasília e a terceira é a via alternativa que se estabeleceu para relações entre os agentes dentro do estado e os agentes na sociedade chamados de anéis burocráticos.

Através do histórico que apresenta o surgimento das ocupações irregulares no Distrito Federal podemos concluir que a forma atotada para gestão das terras contribuiu para encorajar o alastramento das ocupações irregulares, mas não pode ser considerado o principal causador deste fenômeno. Outros fatores contribuem para a condição irregular das ocupações no DF como as políticas públicas e o modelo de planejamento urbano adotado. 


\section{Situação Atual do Distrito Federal Diante das Ocupações Irregulares}

As ocupações irregulares geralmente são reconhecidas por se tratarem de grupos menos favorecidos da população que não conseguem se inserir no mercado habitacional e acabam sendo obrigados a ocuparem áreas, que geralmente são de preservação ambiental, cada vez mais distantes dos centros das grandes cidades. Essas ocupações se caracterizam pela falta de infraestrutura que compõe uma cidade e pela precariedade dos assentamentos onde a necessidade predominante é a fixação de moradia.

No entanto, o caso do Distrito Federal é peculiar. Além de contar com ocupações irregulares que se enquadram nos parâmetros de caracterização de favelas, existe uma grande quantidade de ocupações irregulares geradas pela classe média e média alta da população. A configuração setorizada de Brasília também é um fator que contribui para a facilidade de fixação de ocupações irregulares. Uma ocupação irregular é mais um "setor habitacional" da cidade e os equipamentos necessários para que se configure cidade podem ser encontrados em outros setores que se proponham a isso como o setor hospitalar ou setor comercial.

Pioli e Rossin (2006) apontam que a urbanização acelerada ocorrida no Brasil, juntamente com a distribuição de renda desequilibrada, são os geradores de cidades com assentamentos urbanos periféricos refletindo e perpetuando as desigualdades sociais econômicas. Também apresentam que as cidades brasileiras se moldaram de acordo com a ocupação centro-periferia no qual o centro abriga a infraestrutura, equipamentos urbanos, atividades públicas e privadas e habitações da população de maior renda e na periferia há apenas precária previsão de serviços e ocupação pela população de baixa renda. Afirmam que "as ocupações irregulares são reflexo dos ciclos econômicos no crescimento urbano desordenado, na concentração de renda e da ausência do Estado". (PIOLI; ROSSIN, 2006, p.41)

A origem das ocupações irregulares certamente está na falta de oferta de moradia para a população que está à margem do mercado formal, porém, no Distrito Federal foi observado um desdobramento incomum para essas ocupações. $O$ formato passou a ser considerado vantajoso e cada vez mais comum, passando até mesmo a concorrer com o mercado formal.

O crescimento demográfico é a realidade atual do país. Podemos observar nos dados do IBGE (Figura 01) que a população do Distrito Federal deverá crescer, alcançando 3.773 .409 habitantes até o ano de 2030. A organização territorial e urbana deverá estar preparada para abrigar esse crescimento. Além do crescimento demográfico existe a tendência a urbanização, onde cada vez mais será necessária a gestão do território visando adequá-lo à realidade que se estabelece. 
Figura 1 - Progressão Demográfica do Distrito Federal

\section{Distrito Federal}

População total, homens e mulheres 2000-2030

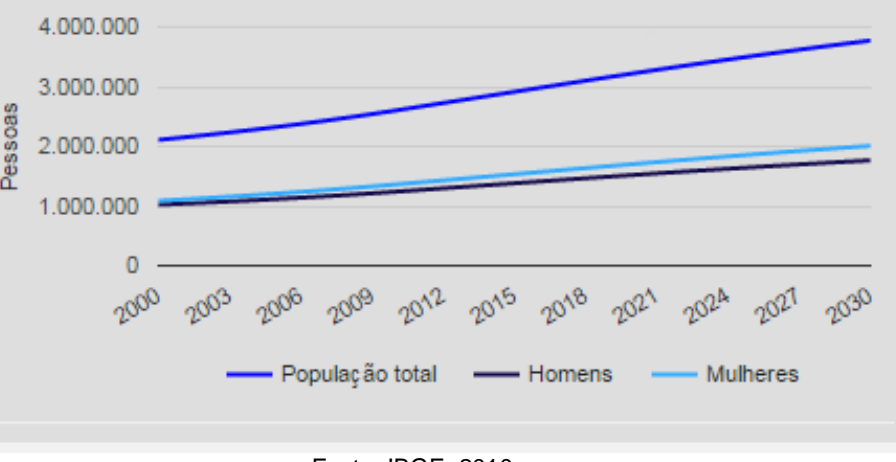

Fonte: IBGE, 2010

O Distrito Federal é um caso atípico de informalidade e por esse motivo, muitas vezes, não existem dados claros e representativos indicados nas pesquisas realizadas. De acordo com dados apresentados por Izaguirre e Costa (2007) cerca de 100 mil famílias residiam em loteamento irregulares no Distrito Federal, o que corresponde a um quarto da população, em um total de 513 parcelamentos. Dados do Censo demográfico realizado pelo IBGE em 2000 apresentam as seguintes informações:

Tabela 1 - Pessoas residindo em assentamentos precários no Distrito Federal

\begin{tabular}{llllll}
\hline $\begin{array}{l}\text { Nome do } \\
\text { município }\end{array}$ & $\begin{array}{l}\text { Pessoas em } \\
\text { Setores } \\
\text { Subnormais }\end{array}$ & $\begin{array}{l}\text { Pessoas em } \\
\text { Setores } \\
\text { Precários }\end{array}$ & $\begin{array}{l}\text { Pessoas em } \\
\text { Setores } \\
\text { Subnormais }+ \\
\text { Setores } \\
\text { Precários }\end{array}$ & $\begin{array}{l}\text { Total de } \\
\text { Pessoas em } \\
\text { todos os Tipos } \\
\text { de Setores }\end{array}$ & $\begin{array}{l}\text { em de Pessoas } \\
\text { Assentamentos } \\
\text { Precários }\end{array}$ \\
\hline Brasília & 28.392 & 41.441 & 69.833 & 1.960 .441 & $3,56 \%$ \\
\hline
\end{tabular}

Fonte: Moysés e Borges (2010) a partir de Censo Demográfico IBGE (2000)

Os ditos "condomínios irregulares" são forma de ocupações comuns do território do Distrito Federal. Brandão identifica que esse formato de moradia ocupa grande parte de setores habitacionais nas imediações da área central do Plano Piloto. Um dado ilustrativo nesse sentido é o papel central das Áreas de Regularização no último Plano Diretor de Ordenamento Territorial (PDOT), aprovado em 2009, durante a quinta legislatura da Câmara Legislativa do Distrito Federal (CLDF), e atualizado em 2012, na sexta legislatura. No plano diretor aprovado durante o governo José Roberto Arruda (2007-2010), foram previstos vinte e nove Setores Habitacionais de Regularização. Dentro destes setores, distinguiam-se 39 Áreas de Interesse Específico - ARINE e 22 Áreas de Interesse Social - ARIS. Fora deles, foram previstas mais 6 ARINE e mais 14 ARIS. Outro tipo de áreas de regularização previstos no plano diretor é chamado de Parcelamento Urbanos Isolados - PUI, em total de 27. Destes, 5 são ARINE e 22 são ARIS. (BRANDÃO, 2013, p. 7).

De acordo com documento técnico elaborado pelo Governo do Distrito Federal (2009) alguns fatores são responsáveis pelo surgimento de parcelamentos ilegais em áreas públicas e privadas. Entre eles estão a indefinição da titularidade da propriedade da terra, carência de moradia, monopólio da comercialização de terras por parte do Estado, falta de política de financiamento para habitação e especulação imobiliária. Também apresenta dados do levantamento realizado pela Secretaria de Estado de Desenvolvimento Urbano e Habitação - SEGETH apontando que o DF abrigava 347 parcelamentos informais, dos quais 317 encontravam-se implantados. A população residente nesses parcelamentos urbanos implantados correspondia a 533.578 habitantes, ou seja, $22 \%$ da população do Distrito Federal. 
Quando Ávila (2013) apresenta a problemática das ocupações irregulares no Distrito Federal apresenta os dados do IBGE que revelam que cerca de 133,5 mil pessoas vivem em aglomerados subnormais no Distrito Federal. Já a Pesquisa por Amostra de Domicílios - PDAD, realizada em 2011 pela Companhia de Desenvolvimento do Distrito Federal - Codeplan, aponta 158 mil domicílios, ou 20\% dos domicílios do DF, com problemas fundiários, totalizando 515 mil pessoas vivendo na irregularidade. Desse total, cerca de $31 \%$, ou 49 mil imóveis, estão em áreas de alto ou média-alta renda.

A maior parte da população residente nos parcelamentos urbanos informais implantados concentra-se na Região Administrativa de Sobradinho - RA V (138.624 hab.), na Região Administrativa de Planaltina - RA VI (107.290 hab.) e na Região Administrativa de Taguatinga (91.253 hab.). A população residente nos parcelamentos urbanos informais implantados divide-se em 369.692 habitantes de baixa renda, 158.484 habitantes de média renda e 5.402 habitantes de alta renda.

Brandão (2013) observa que há um predomínio de abordagens cujo foco é o planejamento urbano. As soluções apontadas são técnicas e desconsideram o peso das decisões políticas no processo que levam a irregularidade das ocupações.

O problema das ocupações irregulares vai muito além da esfera técnica. Grande parte das ocupações são resultado da inatividade do agente público, sendo influenciado pelo poder político. Pioli e Rossi (2006) ressalvam que a inação dos agentes públicos ocorre tanto quando se trata da população de baixa renda quanto de alta renda. Isso é claro quando observamos que o poder político atua em ambas as classes e se beneficia dessa situação. Quando se trata da baixa renda há a promessa de moradia2 e para a média e alta renda a promessa de regularização valorizando a área de ocupação e incentivando a especulação imobiliária.

Processos políticos e características organizacionais do estado que produzem fragilidades que afetam o modelo informal de moradia destinados a faixa de média e alta renda. A instabilidade institucional vigente tem favorecido a permanência da irregularidade fundiária.

As leis e decretos se sobrepõe gerando ambiguidades e conflitos que favorecem a manutenção da situação de irregularidade. Além disso, as reconfigurações da administração pública que ocorrem com frequência, descontinuam os trabalhos de acordo com apoio político ao governante que se apresenta no poder minando as capacidades administrativas de políticas que sobrevivam ao longo do tempo.

Dificuldade de alteração da trajetória de expansão urbana informal dos condomínios, em termos operacionais e políticos, é devida a complexidade do problema. Além de interesses e incentivos gerados pelas instituições e expectativas dos indivíduos que comercializam imóveis e prestam serviços no interior dos condomínios.

\section{Aplicação das Definições de Ocupações Irregulares}

A cada dia são criadas e discutidas novas nomenclaturas para definição das ocupações irregulares. Até mesmo o termo utilizado pelo IBGE, que tenta englobar a maior parte desses assentamentos é questionado. Gondim (2010) propõe uma substituição do termo aglomerados subnormais por "assentamentos precários" afirmando que corresponderia melhor as transformações recentes da problemática habitacional brasileira.

No Distrito Federal o termo adotado é "condomínios" o que não altera a sua situação de irregularidade. Continua sendo um aglomerado subnormal ou uma favela independentemente do nível de renda da população que ocupa essas áreas.

Rolnik (2004) discorre que o surgimento de habitações subnormais são resultado da impossibilidade de

2 Engloba todos os componentes necessários para o morar digno que são: saneamento, infraestrutura, serviços e equipamentos urbanos. 
adequação da totalidade da população as regras impostas pela normatização do Estado e indica a necessidade apontada por essa parcela da população de reconhecimento e possibilidade de inserção no mercado da cidade. Tais argumentos são adequados a situação vivida pela população de baixa renda, porém, quando se trata da população de média e alta renda, que muitas vezes deixa o imóvel regular para adquirir um irregular, existem outros motivos intrínsecos que não se justificam pela impossibilidade de adequação as regras.

Em ambas as situações são uma parcela da população que não se insere nas regras de ordenamento territorial, independentemente da denominação atribuída a área que ocupa ou do motivo que a levou a assumir tal forma de ocupação.

Mais importante do que uma definição que englobe todas as formas de ocupações irregulares ou de definições que demostrem as peculiaridades de cada uma delas é a busca de uma solução para o problema que afeta milhares de pessoas, inclusive as que não se inserem diretamente no formato de ocupações discutido.

Maricato (2011) indica a necessidade de afirmação do controle do Estado frente ao uso e ocupação do solo, considerando a conflituosa realidade urbana brasileira que cresce desgovernada.

As políticas urbanas precisam ser consistentes, preparadas e adequadas para o formato que atenda às necessidades sociais e econômicas da população como um todo.

\section{Considerações Finais}

O histórico abordado permite perceber que o problema das ocupações irregulares é antigo e antecede a atual definição de condomínios atribuída aos assentamentos. As definições buscam identificar e classificar as ocupações irregulares, mesmo que isso não contribua para a solução do problema e só gere mais dificuldades quanto à obtenção de dados que revelem a real dimensão da problemática.

O Distrito Federal é um caso peculiar quando se trata do tema de ocupações irregulares, uma vez que pode ser observado em seu território fenômeno crescente de ocupações irregulares promovidos pela população de média e alta renda.

A partir da reflexão realizada sobre a problemática, desde suas origens, passando por suas definições e causas, além de tentativa de delinear sua situação atual, foi identificada a necessidade de dados mais precisos e sólidos que permitam quantificar e qualificar as ocupações irregulares do Distrito Federal e dessa forma subsidiar estudos que proponham medidas mitigadoras e preventivas para o problema abordado.

\section{Referências}

AVILA, Paulo. Mais regularização da ocupação do solo é melhor?. Ipea, ano 10, ed. 76, 2013. Disponível em:

http://www.ipea.gov.br/desafios/index.php?option=com_content\&view=article\&id=2900:catid=28\&ltemid =23>. Acesso em: 15 de abril de 2016 .

BRANDÃO, Igor Dias Marques Ribas. Por que falha a regularização? Fragilidade institucional e (in)capacidades estatais no Distrito Federal. 2013. Dissertação de Mestrado, Instituto de Ciência Política, Universidade de Brasília, Brasília, 2013.

GONDIM, Linda M. P. Habitação popular, favela e meio ambienta. In: ENANPARQ, 2010, Rio de Janeiro, 2010.

GOVERNO DO DISTRITO FEDERAL. Documento Técnico do Plano de Ordenamento Territorial PDOT. Secretaria de Estado Desenvolvimento Urbano e Meio Ambiente - SUDUMA, 2007. 
INSTITUTO BRASILEIRO DE GEOGRAFIA E ESTATÍSTICA (IBGE). Aglomerados Subnormais: informações territoriais. Rio de Janeiro, p.1-251, 2010.

IZAGUIRRE, Mônica; COSTA, Raymundo. Brasília abre guerra contra construções em condomínio fora da lei. In: Valor Econômico. Especial, p. A16, 2007. Disponível em: $<$ www2.senado.leg.br/bdsf/bitstream/handle/id/479955/noticia.htm?sequence=1> Acesso em: maio 2016.

LORENZETTI, Maria Sílvia Barros. A questão habitacional no Brasil. Consultoria Legislativa. Câmara dos Deputados, Brasília, 2001.

MARICATO, Erminia. A cidade sustentável. In: CONSEGE, 2011, Rondônia. 2011. p. 11-32. Disponível em: $\quad<$ http://www.sengemg.com.br/downloads/eventos/9_consenge/caderno-teses-2Consenge.pdf> Acesso em: maio 2016.

MOURA, Cristina Patriota de. As trajetórias da formalização: condomínios horizontais. In: $32^{\circ}$ ENCONTRO ANUAL DA ANPOCS. GT 01: A cidade nas ciências sociais: teoria, pesquisa e contexto, 2008.

MOYSÉS, Arisitides; BORGES, Elcileni de Melo. A questão e aferição de Habitações Subnormais: informações de Goiás e RMG. Observatório das Metrópoles. Goiânia, 2010. Disponível em: $<$ http://www.observatoriodasmetropoles.net/download/gthab/Textos_ref/03_Ary_Elcileni.pdf> Acesso em: 17 abril 2016.

PIOLI, Maria Sulema M. de Budin; ROSSIN, Antonio Carlos. O meio ambiente e a ocupação irregular do espaço urbano. Revista Brasileira de Ciências Ambientais. São Paulo, n.3, p. 40-53, abr. 2006.

ROLNIK, Raquel. O que é cidade. São Paulo: Ed. Brasiliense. 2004.

SOUZA, Ângela Gordilho. Favelas, invasões e ocupações coletivas nas grandes cidades brasileiras (re)qualificando a questão para Salvador-BA. Caderno Metrópole. n. 05, p. 63-89 2011.

TERRACAP. Histórico. Brasília: Agência de Desenvolvimento do Distrito Federal, 2016. Disponível em: $<$ http://www.terracap.df.gov.br/regularizacao-fundiaria-novo-2/historico-7> Acesso em: 20 maio 2016. 